\title{
Vulnerability, resilience and resistance in diverse societies
}

$\mathrm{T}$ his issue of Approaching Religion includes two articles presented at the fifteenth ETMU Conference, which was held at Åbo Akademi University in Turku on 15-16 November 2019. The conference was organized by the Society for the Study of Ethnic Relations and International Migration (ETMU) and the Institute for Human Rights and the Minority Research Profile at Åbo Akademi University, in cooperation with the Migration Institute of Finland, the Turku Network for Research on Multiculturalism and Societal Interaction (Turku McNet) at the University of Turku, and the Donner Institute. ETMU is a multidisciplinary scientific society, which was established in 2003 to promote research on ethnic relations and international migration in Finland, including topics such as integration, forced migration, multiculturalism, racism, nationalism, minority rights, national minorities, citizenship, and other related subjects.

The conference theme was 'Vulnerability, Resilience and Resistance in Diverse Societies', and the goal was to explore meanings of and resistances towards vulnerability in the context of mobility, migration, and minoritization. The keynote speeches and workshop presentations discussed the conference themes from a variety of perspectives, including the research ethics of studying vulnerability, political mobilization for migrants' rights, the construction of vulnerable identities, the effects of migration policy changes on vulnerable groups, and ageing and death in diverse societies.

One of the workshops explored categorizations pertaining to migrants. More specifically, the workshop asked how these categorizations influence migrants' status in society, and how categories - created, for instance, through migration legislation - may also produce social realities for mobile people, not only in terms of their legal access to a country but also, more informally, in terms of what opportunities are available for migrants once they have settled in a country (e.g. in education or in the labour market). The papers included in this issue deal with migration in and to the European Union (EU). What is fascinating about both of these papers is that they make it clear that even within the idea of 'free movement' in the EU, there are several hierarchies at play. Saila Heinikoski's paper focuses on how mobility within and to the EU is represented in three EU textbooks, used in general upper secondary schools or vocational schools in Finland. She shows that while intra-European mobility 
was represented in the books as a rational, economic, and typically temporary activity, migrants from outside the EU were described using problematizing terms; for instance, as an uncontrollable 'flow' that jeopardizes the future of European welfare systems. Refugees' and asylum-seekers' rights to protection were not mentioned in any of the books. The effect was that the concept of 'vulnerability' became attached to Europe itself: the metaphors related to natural forces led to the idea that it is the European project that is in danger due to 'uncontrollable' migration from outside the EU. As Heinikoski writes, 'European mobility and communality still seem to be to a great extent based on the exclusion of others and construction of otherness in response to an ostensible threat coming from the outside'.

Solange Maslowski, on the other hand, examines categorizations of EU migrants into different groups based on her analysis of directives, treaties, and other official documents of the EU, the European Commission, and the Court of Justice of the EU (CJEU). She shows how, especially since 2010, there has been an increasing 'reinforcement of the differentiation between active and non-active EU migrants. The member states are clearly making a division between 'welcome' and 'unwelcome' movers, the main distinction being economic activity. This categorization between 'good and bad mobile EU citizens', as Maslowski puts it, has no basis in any legal provision, but it is still visible, for instance, in CJEU rulings (and, of course, in political and public debates in the EU). In addition, the categorization was visible in older member states' opposition to granting free movement to citizens of many Eastern European countries during the EU's enlargement. Both Maslowski and Heinikoski show that the Roma minority, in particular, comes to be represented as unwanted in various categorizations and representations. They are racialized as an economically inactive, poor, and possibly dangerous mobile group that many states would like to exclude from 'free movement' altogether. As Maslowski poignantly puts it, these categorizations reveal the 'weaknesses of EU Citizenship and of the EU project'. While the schoolbooks celebrate free movement as 'the most important right of EU citizens', this freedom does not seem to apply to the more disadvantaged EU citizens.

In research on migration and minorities, and in the contemporary human rights discourse more broadly speaking, the concept of vulnerability is often used to refer to individuals and groups whose rights are perceived to be at a particular risk, such as refugees, undocumented migrants, or migrant children. It seems that the trend in many countries in Europe (and beyond) is to further securitize migration, to frame migration as a security risk, and to increasingly limit legal migration routes. These are processes than can create vulnerability by pushing migrants to the margins of societies or onto precarious migration routes. Heinikoski's and Maslowski's papers show that even EU citizenship does not grant protection against vulnerability in the context of EU migration. In fact, in public and political debates (and even in schoolbooks), the EU itself is increasingly portrayed as 'vulnerable' because of global forces that allegedly threaten the stability in European welfare regimes. In other words, the papers show that the term 'vulnerability' can be abused to merely maintain global power relations, where the division between the 'West and the Rest' becomes strengthened.

Johanna Leinonen \& Elina Pirjatanniemi Guest editors 


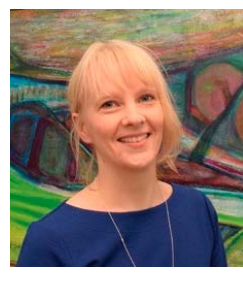

Johanna Leinonen is Academy Research Fellow at the Migration Institute of Finland in the project 'Refugee Journeys: Narratives of Forced Mobilities' (Academy of Finland, 2018-23). Her fields of expertise include migration and refugee history, family reunification and family separation, transnationalism, and marriage migration.

Elina Pirjatanniemi is Professor of Constitutional and International Law, and the Director of the Institute for Human Rights at Åbo Akademi University in Turku, Finland. Her current research interests include vulnerable groups with a

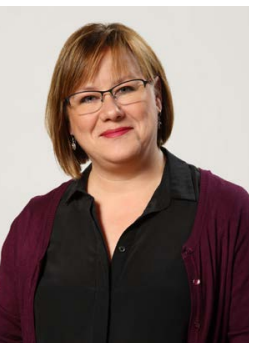
particular focus on irregular migration. 